\title{
Griginal Ofrticle
}

\section{Isolation and identification of $E$-coli 0157:H7 amongst Sudanese patients with bloody diarrhea and in animals Musa $\mathrm{HA}^{1}$, Shikieri $\mathrm{AB}^{2}$, Ahmed $\mathrm{HH}^{3}$, Kafi $\mathrm{SK}^{1}$}

\begin{abstract}
:
E.coli 0157:H7 is present as a commensal in the intestine of animals and as a pathogen in human beings. It causes bloody diarrhoea due to the secretion of a verotoxin which may lead to lethal complications.

Objective: This study is aimed at determining the presence of this organism in animals and patients.

Methods: Rectal swabs were collected from 250 cows. Stool specimens were obtained from 200 patients presenting with macroscopically or microscopically bloody diarrhoea. All specimens were cultured on sorbitol MacConkey agar and incubated at $37^{\circ} \mathrm{C}$ overnight. Non-sorbitol fermenting colonies were identified by different biochemical and serological tests as E.coli 0157:H7. Antibiotic sensitivity was done for the isolates using ampicillin, cephalexin, ciprofloxacin, co-trimoxazole, gentamicin, and tetracycline.

Results: Patients $(\mathrm{n}=10,5 \%)$ with bloody diarrhoea were found to harbour E.coli 0157:H7 in their stools. All isolates (in humans) were resistant to ampicillin. Eight (80\%) were resistant to tetracycline and cephalexin, six $(60 \%)$ to co-trimoxazole, and four $(40 \%)$ to gentamicin. All isolates were sensitive to ciprofloxacin. Sixty percent of the human isolates were resistant to three antibiotics and $40 \%$ to four antibiotics. Twenty of the cows $(8 \%)$ were found to be carriers of E.coli 0157:H7. All isolates (in animals) were resistant to ampicillin, five (25\%) to tetracycline and cephalexin and four $(20 \%)$ to co-trimoxazole. All animal isolates were sensitive to gentamicin and ciprofloxacin. Thirty five percent of the animal isolates were resistant to two antibiotics and $25 \%$ to three antibiotics.

Conclusion: The isolation of E.coli 0157:H7 from animals and patients should direct the attention of physicians and paediatricians to consider the possibility of infection and complications by this organism.
\end{abstract}

Key words: Antibiotic sensitivity, sorbitol MacConkey agar, serological tests.

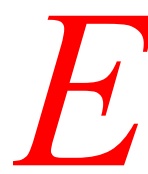

-coli is a member of the normal intestinal flora of both human and warm blooded animals and birds. Most of E-coli infections are opportunistic infections of the bladder, kidney, wounds and meningitis. It is one of the important nosocomial pathogens. The strains capable of causing such diseases possess one or more virulent factors that are not found in E-coli strains comprising the normal flora. Special strains of E-coli can cause diarrhea; one of which is the verotoxigenic $E$-coli ${ }^{1}$.

\footnotetext{
1. The National Ribat University, Sudan

2. Taibah University, Saudi Arabia

3. University of Sciences and Technology, Sudan Correspondence: Prof. Hassan A. Musa.Tel. no. +249912393971. E-mail: hasanaziz15@yahoo.com
}

The verotoxin is encoded on the genome of bacteriophages which enter E-coli via phageconversion $^{1,2}$. In 1982 one particular serovar of E-coli $0157: \mathrm{H} 7$ was identified as a causative agent involved in two outbreaks of distinctive bloody diarrhoea syndrome ${ }^{3,4}$. Since then, the organism has received much attention, not only in the United States but in other countries as well, as a cause of sporadic or epidemic bloody diarrhea and non bloody diarrhea, Haemolytic Uremic Syndrome (HUS) and Thrombotic Thrombocytopenic Purpura (TTP).

Different verotoxin-producing $E$-coli serovars have so far been isolated from human, animals and food stuff. E-coli $0157: \mathrm{H} 7$ is believed to live in the intestine of cattle, 
chicken, sheep and swine ${ }^{5}$. The organism is able to survive in bovine feces, food, water, manure and crops for an extended period of time (weeks to months). Meat can become contaminated during slaughter ${ }^{6}$. Person to person is an important mode of transmission through the oral fecal route ${ }^{7,8}$. Although most patients recover from E-coli 0157:H7 infections, about $5-10 \%$ of the infected individuals develop HUS. E-coli $0157: \mathrm{H} 7$ is also responsible for $90 \%$ of the cases of HUS. In fact some researchers believe that $E$ - coli 0157:H7 is the only cause of HUS in children. Among the elderly, HUS is associated with fever and neurological symptoms usually due to TTP $^{9}$. Among the survivors of HUS, $5 \%$ eventually develop end stage-renal-failure with the resultant need for dialysis or transplantation.

The highest rate of isolation of E.coli 0157:H7 is from fecal specimens from children and elderly patients ${ }^{10}$. E-coli 0157:H7 can also be isolated by the culture of stools and the normal routine biochemical and serological tests ${ }^{11}$. The verotoxin can be detected using vitro cell assay, latex agglutination ELISA, multiplex PCR and randomly amplified polymorphic DNA ${ }^{12,13}$. The majority of the strains of E-coli 0157:H7 are susceptible to the commonly used antimicrobials but resistance is very high to azithromycin ${ }^{14}$.

The present study was meant to look for the presence of E.coli 0157:H7 in patients presenting with bloody diarrhea as well as in cattle.

\section{Materials and methods:}

This study was carried out in Khartoum State from February until August 2008. It included 200 patients presenting with macroscopically or microscopically bloody diarrhea and 250 cattle from three farms in Khartoum State. All of which were investigated for the carriage of E-coli O157:H7. Fecal specimens were collected from the patients and rectal swabs from the cattle in clean containers. Direct microscopy of the stool specimens was done to exclude any protozoan infection. The specimens were cultured on $1 \%$ sorbitol MacConkey agar and incubated at $37^{\circ} \mathrm{C}$ overnight. On the following day, non sorbitol fermenting colonies were identified using biochemical and serological tests as E-coli 0157:H7. Antibiotic susceptibility of the isolates was carried out using six antibiotics' discs which were: ampicillin $10 \mu \mathrm{g}$, cephalexin $30 \mu \mathrm{g}$, ciprofloxacin $5 \mu \mathrm{g}$, cotrimoxazole $25 \mu \mathrm{g}$, gentamicin $10 \mu \mathrm{g}$ and tetracycline $30 \mu \mathrm{g}$ and were reported according to the NCCL recommendations ${ }^{15}$.

\section{Results:}

Out of the 200 fecal specimens collected from the patients presenting with bloody diarrhea, ten $(5 \%)$ were found to be positive for E-coli 0157:H7 (Fig 1).

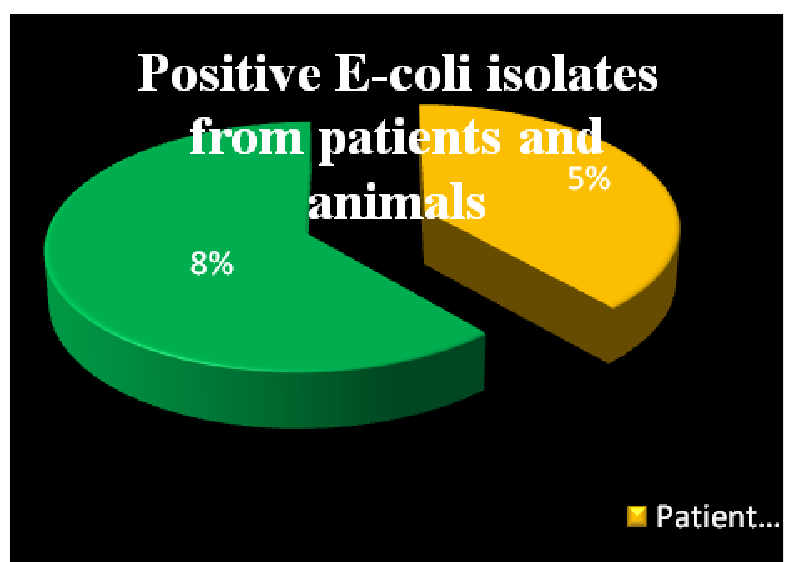

Fig 1: The percentage of E-coli 0157:H7 isolates from patients and animals.

All isolates were resistant to ampicillin, eight $(80 \%)$ to tetracycline and cephalexin, six $(60 \%)$ to co-trimoxazole and four $(40 \%)$ to gentamicin. Moreover, all isolates were sensitive to ciprofloxacin (Fig. 2).

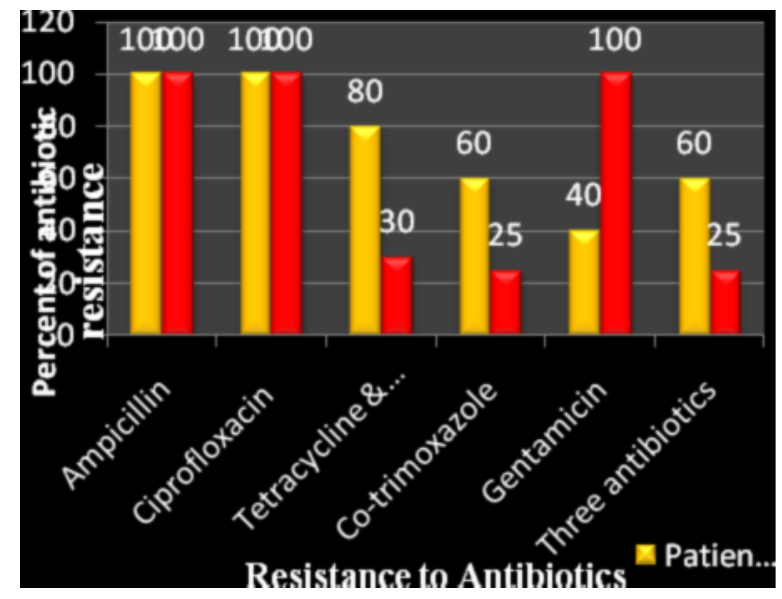

Fig 2: The percentage of antibiotic resistance 
of E.coli $0157: \mathrm{H} 7$ isolates from patients and animals.

Sixty percent of the human isolates were resistant to three antibiotics and $40 \%$ to four antibiotics.

Out of the 250 cows, twenty (8\%) were positive for E-coli 0157:H7 (Fig 1). The isolates were all resistant to ampicillin. Six $(30 \%)$ of the isolates were resistant to tetracycline and cephalexin and four $(25 \%)$ to co-trimoxazole. All of the isolates were sensitive to ciprofloxacin and gentamicin (Fig 2). Multi drug resistance was common amongst the isolates. Thirty five percent of the animal isolates were resistant to two antibiotics and $25 \%$ to three antibiotics.

\section{Discussion:}

Verocytotoxin producing E-coli 0157:H7 emerged as a major food borne zoonotic pathogen in during the 1980s and 1990s. The disease was often severe with significant mortality in young and elderly patients ${ }^{16}$. It can cause haemorrhagic colitis, Haemolytic Uraemic Syndrome and Thrombotic Thrombocytopenic Purpura. The organism can be isolated from the intestine of different animals but it seems that the main reservoir is cattle $^{8}$. The percentage of E- coli $0157: \mathrm{H} 7$ isolated from patients suffering from bloody diarrhoea in the current study was 5\% which is similar to findings by the $\mathrm{MMWR}^{17}$. Different results were reported by Elmer ${ }^{18}$.

Furthermore, the current isolates showed resistance to the commonly prescribed antibiotics like ampicillin (100\%), tetracycline and cephalexin (80\%), cotrimoxazole $(60 \%)$ and gentamicin $(40 \%)$. The isolates were fully sensitive to ciprofloxacin. The increase in resistance to the commonly used antibiotics is well known and stated in previous studies. Most of the isolated E-coli 0157:H7 (97\%) during the year 1988, were sensitive to ampicillin tetracycline and co- trimoxazole ${ }^{19}$. Alvaro and co-workers $^{20}$ found that resistance of the organism to ampicillin, tetracycline and cotrimoxazole was increasing. In 1999, Banerjee et $a l^{21}$ found that most of the strains of $E$ - coli 0157:H7 were resistant to ampicillin and tetracycline.
The present study documented the first report of the presence of carriers of this organism amongst cattle in Khartoum State. The percentage of the carriers in cattle was found to be $8 \%$. Similar range of carriers among cattle was reported by different authors 3,13 . High percentage of carriers was reported by Lothar and colleagues in $1993^{22}$. The variability in the percentages of carriers can be attributed to the different methods of sampling and culturing techniques. The antibiotic susceptibility of the animal's isolates seems to be more sensitive than the human's isolates. This can be explained by the fact that antibiotics are commonly used and routinely prescribed in hospitals.

\section{Conclusions:}

The isolation of E-coli $0157: \mathrm{H} 7$ from patients and animal carriers should direct the attention of the physicians and pediatricians to the possibility of the appearance of its complications among young and elderly patients.

\section{References:}

1. Wesley A, Volk David CB, Robert JK et al. Enteric and related gram negative organisms IN Essentials of Medical Microbiology $4^{\text {th }}$ ed 1991. J.B. Lippincott, Co. Philadelphia, USA.

2. Walker S. Bacteria and Bacterial diseases, surface antigens of enteric organisms IN Saunders Text and Review Microbiology 1998: Saunders CO, USA.

3. Montenegro MA, Kim HM, Medical B et al.. Detection and characterization of fecal verotoxin-producing E.coli from healthy cattle. J Clin Microbiol 1990; 28(6):1417-21.

4. Riley LW, Remis RS, Helgerson SD. Haemorrhagic colitis associated with a rare E.coli serotype. $J \quad N$ Eng Med 1983; 308(12):681-5.

5. Friedman MS, Rocles T, Koehler JE et al. E.coli 0157:H7 outbreak associated with an improperly chlorinated swimming pool. J Clin Inf Dis 1999; 219:298-303.

6. Kim JY, Kim MH, Kwon NH et al. Isolation and identification of E-coli 0157:H7 using different detection methods and molecular determination by multiplex PCR and RAPD. J Nat Sci 2005; 6(1):7-9.

7. Center for Diseases Control (CDC). Division of bacterial diseases information. E coli 0157:H7 2001. 
8. World Health organization. Escherichia coli 0157:H7. Fact sheet no 125, 1996.

9. Cody SH, Glyan MK. An outbreak of E.coli 0157:H7 infection from unpasteurized apple juice. Ann Intern Med 1999; 130:202-9.

10. Laurence S, Auer A, Katherine DG et al. E.coli 0157:H7 diarrhoea in United States. Clinical and epidemiological features. J Am Intern Med 1997; 126(7):505-13.

11. Connie RM, George M. Laboratory identification of significant isolates IN Text book of Diagnostic Microbiology. Part $112^{\text {nd }}$ ed 2000; WB Saunder Co, USA.

12. Karmali MA, Martin P, Martina B. Evaluation of microplate agglutination method (Vorolox-F assay) for detection and characterization of verotoxin in E.coli. J Clinc Microbiol 1999; 37(2):396-9.

13. Wani SA, Bhat MA, Samanta I et al. Isolation and characterization of shiga toxin producing E.coli and EPEC from calves and lambs with diarrhoea in India. Lett App Microbiol 2003; 37(2):121-6.

14. Reyes MS, Duran CT, Prado UJ. Antimicrobial susceptibility of shiga-toxin-producing E.coli strains isolated from infection and food. Rev Med Chd 2004; 132(10):1211-6.

15. World Health organization Draft: Manual antimicrobial resistance and susceptibility testing. WHO antimicrobial resistance monitoring program 1997. WHO, Geneva.

16. Thorn CJ. Bacterial food-borne zoonosis. Rev Sa Tech 2000; 19(1):226-39.

17. Morbidity and Mortality Weekly Reports (MMWR). Outbreak of acute gastroenteritis attributable to Escherichia coli serotype 0104:H21. Helena Montana 1995; 44(27): 501-3.

18. Elmer WK, Stephan DA, William MJ et al. The enterobacteriaceae: Colour Atlas and Text Book of Diagnostic Microbiology $5^{\text {th }}$ ed 1997. Lippineott Pub, New York, Philadelphia.

19. Samuel R, Sandra BM, Rafig A et al. Characterization of Escherichia coli serotype 0157:H7 J Clin Microbiol 1988; 26(10): 2006-12

20. Alvaro C, Valeria $\mathrm{P}$, Leonardo $\mathrm{M}$ et al. Enterohaemarrhagic E-coli associated with haemolytic uraemic syndrome in Chilean children. J Clin Microbiol 1992; 30(8):2153-7.

21. Banerjee R, Kapoor KN, Ghatak S. Isolation of verotoxin producing $E$ - coli from diarrhea and urinary tract infection patients. $J$ Commun Dis 1999; 31(3):161-4.

22. Lothar B, Dorothee G, Hartmut $S$ et al. Prevalence of some properties of verotoxin producing E-coli in seven different species of healthy domestic animals. J Clinic Microbiol 1993; 